\title{
Knowledge, attitude, and practice of patients with type 2 diabetes mellitus with regard to their disease: a cross-sectional study among Palestinians of the West Bank
}

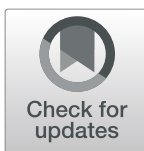

Ramzi Shawahna ${ }^{1,2^{*}}$, Saed Samaro ${ }^{3}$ and Zaid Ahmad ${ }^{3}$

\begin{abstract}
Background: In Palestine, type 2 diabetes mellitus (T2DM) is a rapidly growing health concern. This study evaluated knowledge, attitude, and practice of patients with T2DM with regard to their disease. The study also investigated association and correlation between knowledge, attitude, and practice with sociodemographic and clinical characteristics of the patients. Predictors of higher knowledge, positive attitude, and good practice were also identified.

Methods: This cross-sectional study was conducted in primary healthcare facilities frequently visited by patients with T2DM across the West Bank of Palestine in the period of October 2018 to January 2019. An interviewer administered questionnaire was used to determine knowledge, attitude and practice of patients with T2DM with regard to their disease.

Results: Out of 300 patients invited, 220 (73.3\%) patients responded. In this study, the median age was 57.0 years (51.0, 65.0), the median time elapsed since diagnosis with T2DM was 7.0 years $(4.0,14.0)$, the median fasting blood glucose was $150.0 \mathrm{mg} / \mathrm{dL}(128.8,180.0)$, the median postprandial glucose was $230.0 \mathrm{mg} / \mathrm{dL}$ (200.0, 270.0), the median $\mathrm{HbA}_{1 \mathrm{c}}$ was $7.8 \%(7.0,8.53)$, and the median BMI was $28.8 \mathrm{~kg} / \mathrm{m}^{2}(25.5,33.1)$. The median knowledge score was 6.0/13.0 (4.5/13.0, 7.5/13.0), the median attitude score was 3.0/4.0 (2.0/4.0, 4.0/4.0), and the median practice score was 3.0 (1.0/5.0, 4.0/5.0). Having university education was strongly associated with having higher knowledge scores $(p$-value $=0.001)$. Additionally, having attended an educational program on diabetes was moderately associated with higher practice scores ( $p$-value $=0.026$ ).

Conclusions: Findings of this study highlighted the need for appropriately designed interventions to increase knowledge about T2DM among patients with low educational level. Well-designed educational programs might promote healthy practice among patients with T2DM. Future studies are still needed to assess if such interventions could be effective in improving health outcomes and quality of life of patients with T2DM in Palestine.
\end{abstract}

Keywords: Associated factors, Attitude, Diabetes mellitus, Knowledge, Palestine, Practices

\footnotetext{
*Correspondence: ramzi_shawahna@hotmail.com

${ }^{1}$ Department of Physiology, Pharmacology and Toxicology, Faculty of Medicine \& Health Sciences, New Campus, Building: 19, Office: 1340, An-Najah National University, P.O. Box 7, Nablus, Palestine

${ }^{2}$ An-Najah BioSciences Unit, Centre for Poisons Control, Chemical and Biological Analyses, An-Najah National University, Nablus, Palestine Full list of author information is available at the end of the article
}

(c) The Author(s). 2021 Open Access This article is licensed under a Creative Commons Attribution 4.0 International License, which permits use, sharing, adaptation, distribution and reproduction in any medium or format, as long as you give appropriate credit to the original author(s) and the source, provide a link to the Creative Commons licence, and indicate if changes were made. The images or other third party material in this article are included in the article's Creative Commons. licence, unless indicated otherwise in a credit line to the material. If material is not included in the article's Creative Commons licence and your intended use is not permitted by statutory regulation or exceeds the permitted use, you will need to obtain permission directly from the copyright holder. To view a copy of this licence, visit http://creativecommons.org/licenses/by/4.0/ The Creative Commons Public Domain Dedication waiver (http://creativecommons.org/publicdomain/zero/1.0/) applies to the data made available in this article, unless otherwise stated in a credit line to the data. 


\section{Background}

Type 2 diabetes mellitus (T2DM) is a major metabolic disease that is characterized by sustained high levels of blood glucose which result from defective secretion of insulin, ineffective insulin action, or both $[1,2]$. Globally, T2DM is considered a major public health epidemic with considerable number of premature deaths, disabilities, high morbidity, and mortality rates [3]. According to recent estimates, about 462 million people were affected by T2DM in 2017 which corresponded to approximately $6.3 \%$ of the world's population [4]. Today, T2DM is the 9th leading cause of mortality that claims 1 million human lives on an annual basis. In Palestine, T2DM is a rapidly growing health concern. The prevalence of T2DM in the general Palestinian population was estimated at $15.3 \%$. The prevalence rate was forecasted to increase to $20.8 \%$ for 2020 and $23.4 \%$ for 2030 [5].

Complications associated with T2DM include hypoglycemia, hyperosmolar hyperglycemic state, diabetic ketoacidosis, retinopathy, nephropathy, neuropathy, and cardiovascular events [6,7]. Today, T2DM is a major cause of lower limb amputations $[8,9]$. Interestingly, complications associated with T2DM might be mitigated by adherence to proper management approaches which aim to achieve optimal glycemic control and/or decrease macro- and microvascular complications of T2DM [10-12]. Management of T2DM involves both lifestyle modifications and pharmacological therapy [13]. Achieving optimized patient health outcomes requires high levels of knowledge of the disease, access to insulin and other oral hypoglycemic agents, and equipment to monitor blood glucose [14].

Recent studies that were conducted to assess knowledge, attitude, and practice of patients with T2DM highlighted the necessity of higher awareness among patients with regard to preventing, diagnosis, mitigating risk factors, and minimizing complications of the disease [15-18]. It has been argued that educating patients on their disease was an effective strategy to reduce complications of T2DM and achieve improved control over blood glucose $[19,20]$. Probably, higher knowledge could improve attitude and practice of the patients with regard to their disease. Previous studies have shown that patients who were informed about their T2DM and the complications associated with the disease reported improved adherence to treatment compared to patients who had poor knowledge of T2DM and the complications associated with the disease. It has been argued that patients with T2DM who are knowledgeable of their disease would achieve better control of their blood glucose [21]. This might improve the health and quality of life of the patients. Additionally, unfavorable attitudes were associated with poor control over blood glucose and incidence of complications [22]. Previous studies have shown differences in knowledge, attitude, and practice among patients with T2DM in primary and tertiary healthcare settings in Saudi Arabia, Sri Lanka, Ethiopia, and India [3, 15-18].

Although having good knowledge, attitude, and practice regarding T2DM would be helpful in improving patient related health outcomes, currently, little is known on the level of knowledge, attitude, and practice among Palestinians with T2DM with regard to their disease. Therefore, this study was conducted to evaluate knowledge, attitude, and practice among Palestinians with T2DM in the West Bank. The study also investigated association and correlation between knowledge, attitude, and practice with sociodemographic and clinical characteristics of the patients. Predictors of higher knowledge, positive attitude, and good practice were also identified. Findings of this study could inform future decisions and interventions to improve control over blood glucose, reduce the incidence of complications, improve care, and quality of life of Palestinians with T2DM.

\section{Methods}

\section{Study settings and design}

This study was conducted in different primary healthcare facilities that were frequently visited by patients with T2DM across the West Bank of Palestine. Patients were approached and invited to take part in the study by the field researchers. The sample was collected in the period of October 2018 to January 2019 from 9 of the 11 $(81.8 \%)$ primary healthcare facilities in the different governorates of the West Bank of Palestine. The field researchers could not visit and recruit patients from the governorates of Jerusalem and Hebron due to logistic reasons. After obtaining their consent, patients with T2DM were interviewed to determine their knowledge, attitude, and practice toward T2DM. This study was conducted in a cross-sectional design using a validated and reliable study tool. The study tool was tested for reliability in a pilot before conducting the larger study.

\section{Population, inclusion, and exclusion criteria}

The study population was patients with T2DM who visited primary healthcare facilities in the West Bank of Palestine. Patients of both genders who were at least 18 years old and diagnosed with T2DM at least 6 months ago were invited to take part in this study. Patients were included if they provided verbal consent and were willing to respond to questions in a questionnaire.

\section{Sample size and sampling method}

According to the International Diabetes Federation, there were 174,300 patients with T2DM in Palestine [23]. The sample size required for this study was 
calculated using an online sample size calculator (http:// www.raosoft.com/samplesize.html). The sample size was estimated for a population of more than 20,000 with a $95 \%$ confidence interval and accepting a 5\% margin of error. The sample size required for this study was 243 patients with T2DM. A convenience sampling method was followed to recruit participants in this study. Patients with T2DM were approached and recruited by field researchers from different primary healthcare facilities in the West Bank of Palestine.

\section{Study tool}

The study was conducted using a pre-validated and reliable questionnaire to collect data relevant to knowledge, attitude, and practice of patients with T2DM with regard to their disease. The questions included in the questionnaire were informed by relevant literature [24-26]. The questionnaire collected sociodemographic characteristics of the patients like age, gender, body weight, height, marital status, employment, place of residence, educational level, and monthly income. The body weight and height were used to calculate the body mass index (BMI) of the patient [27]. Patient health records were used to obtain the time elapsed since they received their diagnosis with T2DM, if they had a health insurance, if they have had attended an educational program regarding diabetes, their usual fasting plasma glucose level, their usual postprandial plasma glucose level, and their usual glycated hemoglobin $\left(\mathrm{HbA}_{1 \mathrm{c}}\right)$ level. Regarding knowledge, the patients were asked to answer the items regardless of their actual practice. The patients were asked to specify the tests used to diagnose DM, what can be done to keep DM under control, how long patients should continue adhering to diet control/ treatment, and what organs would DM affect. Regarding attitude, the patients were asked to answer the items regardless of their practice. Attitude items included whether occasional eating of sweets was alright, forgetting to take insulin or antidiabetic medications on some says was alright, whether not practicing the recommended exercise was alright, and whether the patients should go for regular checkups even if their blood glucose was under control. Regarding practice, the patients were asked to answer items relevant to their actual practice. Practice items included whether the patients: took insulin and/or other antidiabetic medications as their caring physicians recommended, followed diet schedule as recommended by their caring healthcare providers, adhered to practicing regular exercise as recommended by their caring healthcare providers, whether their blood glucose was under control, and whether they regularly go for follow ups with their caring healthcare professionals.

The data were collected into an interviewer administered questionnaire in face-to-face interviews. The interviewers were final year Doctor of Medicine (MD) candidates who were trained to administer interviews.

\section{Face validity, pilot testing, reliability and internal consistency}

The study tool was reviewed by 5 researchers who had experience in conducting research on T2DM. The researchers who were physicians $(n=3)$ and pharmacists $(n=2)$ rated each item for relevance using a Likert-scale of $1-5$ ( $1=$ not relevant at all, $5=$ highly relevant). Items that were rated as not relevant at all or not relevant by all researchers were excluded. Items that were rated as relevant or highly relevant by all researchers were retained. Equivocal items were resolved by discussion and consensus.

The study tool was pilot tested with 25 patients to assess if the questions were readable and understandable. To test the stability of the scores over a short period of time, the test-retest method was used. The 25 patients were asked to answer the items twice. A short time interval ( $30 \mathrm{~min}$ to $1 \mathrm{~h}$ ) was let between both rounds. Scores obtained in the two rounds were correlated using Pearson's correlation. Excellent stability of scores was indicated by a Pearson's correlation coefficient of $95 \%$ (95\% CI $=91.2$ to $98.7 \%)$ with a $p$-value of $<0.001$. As used in previous studies, acceptable coefficients were set a priori as $>80 \%$ [28-32]. Cronbach's alpha statistics were used to assess the internal consistency of the items used in the study tool. Internal consistency of the items used in the test was good as indicated by a Cronbach's alpha of $74.2 \%$. Acceptable coefficients were set a priori between 70 and $95 \%$.

\section{Data analysis}

For knowledge, attitude, and practice items, the patients were given 1 point for each correct/positive answer and 0 for each incorrect/negative answer. Knowledge scores could range from 0 to 13 , attitude scores could range from 0 to 4 , and practice scores could range from 0 to 5 .

The data obtained in this study were coded and entered into IBM SPSS for Windows v.21.0 0 (IBM Inc., Armonk, New York) for analysis. To determine whether the data were normally distributed or not, Shapiro-Wilk test was used. As determined by the test, the data were not normally distributed. Therefore, the 1st quartile (Q1), 2nd quartile $(\mathrm{Q} 2=$ median), and 3rd quartile (Q3) were used to express the data. The variables: age, time elapsed since diagnosis, BMI, fasting plasma glucose, postprandial plasma glucose, and $\mathrm{HbA}_{1 \mathrm{c}}$ were analyzed as continuous and categorical variables. Categorical data were compared using the Mann-Whitney $U$ test or Kruskal-Wallis test. Spearman's rank correlation was used to assess correlations between variables. To control confounding factors, we conducted a multiple linear 
regression. All variables that were used in the MannWhitney $U$ test and Kruskal-Wallis test were retained in the model. The variables: age, time elapsed since diagnosis, BMI, fasting plasma glucose, postprandial plasma glucose, and $\mathrm{HbA}_{1 \mathrm{c}}$ were included as continuous variables and the coefficients reported were per unit change. However, the variables: gender, marital status, employment, place of residence, educational level, monthly income, having a health insurance, and having attended an educational program were included as categorical variables. Female, single, unemployed, urban, some school, lower income, not having a health insurance, and not having attended an educational program were the reference categories for gender, marital status, employment, place of residence, educational level, monthly income, having a health insurance, and having attended an educational program, respectively. Variance inflation factor (VIF) and tolerance values were used to evaluate collinearity diagnostics. VIF values of $<1.76$ and tolerance values of $>1.01$ indicated absence of multicollinearity issues $[33,34]$. In this study, a $p$-value of $<0.05$ was considered statistically significant. The adjusted $\mathrm{R}^{2}$ with a $p$ value of $<0.05$ was used to evaluate the goodness of fit of the regression model.

\section{Ethics approval and consent to participate}

Ethics approval was obtained from the Institutional Board Review (IRB) of An-Najah National University. Field researchers explained the study design and objectives to the potential participants and obtained their written informed consent before they took part in the present study. The IRB of An-Najah National University approved a verbal consent for this study. Approval was obtained from the Ministry of Health to access the healthcare centers.

\section{Results}

\section{Characteristics of the patients}

Of the 300 patients with T2DM who were initially invited, $220(73.3 \%)$ patients completed the questionnaire. Of the study patients, 138 (62.7\%) were 55 years of age and older, $118(53.6 \%)$ were female, $156(70.9 \%)$ were married, 139 (63.2\%) were unemployed, 149 (67.7\%) resided in urban areas, 55 (25.0\%) has university degrees, 135 (61.4\%) had moderate or high income, 116 (52.7\%) were diagnosed with T2DM 7 or more years ago, 45 (20.5\%) did not have any health insurance, 198 (90.0\%) did not attend any educational program regarding DM, $154(70.0 \%)$ had their usual fasting plasma glucose level of more than $140 \mathrm{mg} / \mathrm{dL}, 177$ (80.5\%) had their usual postprandial plasma glucose level of more than $200 \mathrm{mg} /$ $\mathrm{dL}, 167$ (75.9\%) had their $\mathrm{HbA}_{1 \mathrm{c}}$ level more than 7\%, and $175(79.5 \%)$ had a BMI of more than $25 \mathrm{~kg} / \mathrm{m}^{2}$. Male and female patients significantly differed in relation to their marital status ( $p$-value $=0.001)$, employment status $(p$-value $<0.001)$, and income level $(p$-value $=0.001)$. The median age of the patients was 57.0 (51.0, 65.0) years. The median time elapsed since diagnosis with T2DM was $7.0(4.0,14.0)$ years. The median fasting blood glucose was $150.0(128.8,180.0) \mathrm{mg} / \mathrm{dL}$. The median postprandial glucose was $230.0(200.0,270.0) \mathrm{mg} /$ $\mathrm{dL}$. The median $\mathrm{HbA}_{1 \mathrm{c}}$ was $7.8 \%$ (7.0, 8.53). The median BMI was $28.8(25.5,33.1) \mathrm{kg} / \mathrm{m}^{2}$. There were no statistically significant differences between the continuous sociodemographic and clinical characteristics of the male and female patients ( $p$-value $>0.05)$. Details of the sociodemographic and clinical variables of the patients overall and stratified by gender are shown in Table 1 .

\section{Knowledge, attitude, and practice of the patients with regard to their T2DM}

Knowledge, attitude, and practice of the patients with regard to their T2DM were measured using relevant items. Detailed responses of the patients overall and stratified by their gender are shown in Table 2 .

The median knowledge score of the patients was 6.0 $(4.5,7.5)$. When asked to identify the organs affected by DM, 129 (58.6\%) could identify that DM could affect the eyes and $124(56.4 \%)$ could identify that DM could affect the kidneys. Of the patients, only $82(37.3 \%)$ could identify that DM could affect the heart (Table 3). When asked about how diabetes could be kept under control, the vast majority (90.9\%) of the patients could identify medications including insulin. Diet was identified by 174 (79.1\%) patients. However, going for regular checkups was identified by only $25(11.4 \%)$ patients (Table 2$)$. Distribution of responses were comparable between male and female patients. However, more female patients identified urine tests $(p$-value $=0.022)$ compared to male patients.

The median score of the patient attitude was 3.0 (2.0, 4.0). Of the patients, about $36 \%$ of patients believed that eating sweets occasionally was alright, about $29 \%$ of the patients stated that it was alright if they forgot to take their medicines on some days, around 30\% of the patients believed that it was not necessary to go for regular checkups if their sugar level was under control, and close to $44 \%$ believed that they got enough exercise when doing their daily activity (Table 2). Distribution of responses were comparable between male and female patients ( $p$-value $>0.05)$.

The median practice score of the patients was 3.0 (1.0, 4.0). Of the patients, about $71 \%$ stated that they regularly took their insulin and/or antidiabetic medications as advised by their physicians, about 39\% followed the diet program as advised by their healthcare providers, approximately $37 \%$ stated that they adhered to regular exercises as advised by their healthcare providers, and 
Table 1 Detailed sociodemographic and clinical characteristics of the patients overall and stratified by gender $(n=220)$

\begin{tabular}{|c|c|c|c|c|c|c|c|}
\hline \multirow[t]{2}{*}{ Variable } & \multicolumn{2}{|c|}{ Total } & \multicolumn{2}{|c|}{ Male } & \multicolumn{2}{|c|}{ Female } & \multirow{2}{*}{$\begin{array}{l}p- \\
\text { value }\end{array}$} \\
\hline & $\mathbf{N}$ & $\%$ & $n$ & $\%$ & $n$ & $\%$ & \\
\hline \multicolumn{8}{|l|}{ Age (years) } \\
\hline$<55$ & 82 & 37.3 & 36 & 35.3 & 46 & 39.0 & \multirow[t]{2}{*}{0.580} \\
\hline$\geq 55$ & 138 & 62.7 & 66 & 64.7 & 72 & 61.0 & \\
\hline \multicolumn{3}{|l|}{ Median (Q1, Q3) } & \multicolumn{2}{|c|}{$58.5(50.0,66.0)$} & \multicolumn{2}{|c|}{$56.0(52.0,64.0)$} & 0.598 \\
\hline \multicolumn{8}{|l|}{ Marital status } \\
\hline Single & 32 & 14.5 & 8 & 7.8 & 24 & 20.3 & \multirow[t]{3}{*}{0.001} \\
\hline Married & 156 & 70.9 & 85 & 83.3 & 71 & 60.2 & \\
\hline Divorced/widowed & 32 & 14.5 & 9 & 8.8 & 23 & 19.5 & \\
\hline \multicolumn{8}{|l|}{ Employment } \\
\hline Unemployed & 139 & 63.2 & 38 & 37.3 & 101 & 85.6 & \multirow[t]{2}{*}{$<0.001$} \\
\hline Employed & 81 & 36.8 & 64 & 62.7 & 17 & 14.4 & \\
\hline \multicolumn{8}{|l|}{ Place of residence } \\
\hline Urban & 149 & 67.7 & 72 & 70.6 & 77 & 65.3 & \multirow[t]{2}{*}{0.470} \\
\hline Country side & 71 & 32.3 & 30 & 29.4 & 41 & 34.7 & \\
\hline \multicolumn{8}{|l|}{ Educational level } \\
\hline Some school & 165 & 75.0 & 75 & 73.5 & 90 & 76.3 & \multirow[t]{2}{*}{0.755} \\
\hline University & 55 & 25.0 & 27 & 26.5 & 28 & 23.7 & \\
\hline \multicolumn{8}{|c|}{ Monthly household income (Jordanian Dinar) } \\
\hline$<600$ & 85 & 38.6 & 26 & 25.5 & 59 & 50.0 & \multirow[t]{3}{*}{0.001} \\
\hline $600-1000$ & 93 & 42.3 & 51 & 50.0 & 42 & 35.6 & \\
\hline$\geq 1000$ & 42 & 19.1 & 25 & 24.5 & 17 & 14.4 & \\
\hline \multicolumn{8}{|c|}{ Time elapsed since diagnosis (years) } \\
\hline$<7$ & 104 & 47.3 & 48 & 47.1 & 56 & 47.5 & \multirow[t]{2}{*}{1.000} \\
\hline$\geq 7$ & 116 & 52.7 & 54 & 52.9 & 62 & 52.5 & \\
\hline \multicolumn{3}{|l|}{ Median (Q1, Q3) } & 7.0 & & 7.0 & & 0.442 \\
\hline Has a health insuranc & & & & & & & \\
\hline Yes & 175 & 79.5 & 81 & 79.4 & 94 & 79.7 & 1.000 \\
\hline No & 45 & 20.5 & 21 & 20.6 & 24 & 20.3 & \\
\hline Has attended educat & ggram & ng dia & & & & & \\
\hline Yes & 22 & 10.0 & 6 & 5.9 & 16 & 13.6 & 0.072 \\
\hline No & 198 & 90.0 & 96 & 94.1 & 102 & 86.4 & \\
\hline Fasting plasma gluco & & & & & & & \\
\hline$<140$ & 66 & 30.0 & 29 & 28.4 & 37 & 31.4 & 0.661 \\
\hline$\geq 140$ & 154 & 70.0 & 73 & 71.6 & 81 & 68.6 & \\
\hline Median (Q1, Q3) & & & 150 & & 150. & & 0.703 \\
\hline Postprandial plasma & $(\mathrm{mg} / \mathrm{c}$ & & & & & & \\
\hline$<200$ & 43 & 19.5 & 17 & 16.7 & 26 & 22.0 & 0.394 \\
\hline$\geq 200$ & 177 & 80.5 & 85 & 83.3 & 92 & 78.0 & \\
\hline Median (Q1, Q3) & & & 240 & & 220. & & 0.185 \\
\hline $\mathrm{HbA}_{1 \mathrm{c}}(\%)$ & & & & & & & \\
\hline$<7$ & 53 & 24.1 & 23 & 22.5 & 30 & 25.4 & 0.639 \\
\hline$\geq 7$ & 167 & 75.9 & 79 & 77.5 & 88 & 74.6 & \\
\hline Median (01, 03) & & & 78 & & 75( & & 0.467 \\
\hline
\end{tabular}


Table 1 Detailed sociodemographic and clinical characteristics of the patients overall and stratified by gender $(n=220)($ Continued)

\begin{tabular}{|c|c|c|c|c|c|c|c|}
\hline \multirow[t]{2}{*}{ Variable } & \multicolumn{2}{|c|}{ Total } & \multicolumn{2}{|c|}{ Male } & \multicolumn{2}{|c|}{ Female } & \multirow{2}{*}{$\begin{array}{l}p \text { - } \\
\text { value }\end{array}$} \\
\hline & $\mathbf{N}$ & $\%$ & $n$ & $\%$ & $n$ & $\%$ & \\
\hline \multicolumn{8}{|c|}{ Body Mass Index $\left(\mathrm{kg} / \mathrm{m}^{2}\right)$} \\
\hline$<25$ & 45 & 20.5 & 20 & 19.6 & 25 & 21.2 & 0.867 \\
\hline$\geq 25$ & 175 & 79.5 & 82 & 80.4 & 93 & 78.8 & \\
\hline Median (Q1, Q3) & & & \multicolumn{2}{|c|}{$27.9(25.7,31.8)$} & \multicolumn{2}{|c|}{$29.3(25.4,33.3)$} & 0.464 \\
\hline
\end{tabular}

$\mathrm{HbA}_{1 c}$ Glycated hemoglobin, Q1: 1st quartile, Q3: 3rd quartile, Median = Q2

around $65 \%$ stated that they regularly go for follow ups (Table 2). Distribution of responses were comparable between male and female patients ( $p$-value $>0.05$ ).

There were no statistically significant differences $(p$ value $>0.05$ ) between the overall knowledge, attitude, and practice scores of male and female patients. Details of the knowledge, attitude, and practice scores of the patients stratified by their gender are shown in Table 2 .

\section{Association and correlation between sociodemographic and clinical characteristics of the patients with knowledge, attitude, and practice scores}

When the continuous variables were correlated, there was moderate positive correlation between knowledge, attitude, and practice scores $(p$-value $<0.001)$ scores. Details of these correlations are shown in Table 3.

Knowledge scores correlated positively with monthly income (Spearman's rho $=0.27, p$-value $<0.001$ ) and negatively with age (Spearman's rho $=-0.26, p$-value $<$ 0.001), time elapsed since diagnosis (Spearman's rho $=-$ $0.19, p$-value $<0.001$ ), fasting plasma glucose (Spearman's rho $=-0.24, p$-value $<0.001)$, postprandial glucose (Spearman's rho $=-0.18, p$-value $<0.001$ ), and $\mathrm{HbA}_{1 \mathrm{c}}$ (Spearman's rho $=-0.17, p$-value $=0.015)$. Details of the correlations are shown in Table 3. The median knowledge score was significantly higher for patients who were younger than 55 years old ( $p$-value $<0.001)$, single $(p$-value $=0.021)$, employed $(p$-value $=0.001)$, had university education ( $p$-value $<0.001)$, had higher monthly income ( $p$-value $<0.001)$, diagnosed with T2DM since less than 7 years ( $p$-value $=0.001)$, had usual fasting plasma glucose of less than $140 \mathrm{mg} / \mathrm{mL}(p$-value $=0.003)$, had $\mathrm{HbA}_{1 \mathrm{c}}$ of less than 7\% ( $p$-value $=0.037$ ), and had a BMI of less than $25 \mathrm{~kg} / \mathrm{m}^{2}$ ( $p$-value $\left.=0.039\right)$. Details of the differences are shown in Table 4.

Attitude scores correlated negatively with fasting plasma glucose (Spearman's rho $=-0.24, \quad p$-value < 0.001 ), postprandial plasma glucose (Spearman's rho $=$ $-0.24, p$-value $<0.001), \mathrm{HbA}_{1 \mathrm{c}}$ (Spearman's rho $=-0.14$, $p$-value $=0.048$ ), and BMI (Spearman's rho $=-0.19, p$ value $=0.005$ ). Details of the correlations are shown in Table 3 . The median attitude score was significantly $(p-$ value $=0.013$ ) higher for patients who had usual fasting glucose levels of less than $140 \mathrm{~g} / \mathrm{dL}$ compared to patients who had usual fasting glucose levels of $140 \mathrm{~g} / \mathrm{dL}$ and more. Details of the differences are shown in Table 4.

Practice scores correlated negatively with age (Spearman's rho $=-0.24, p$-value $<0.001)$, time elapsed since diagnosis (Spearman's rho $=-0.30, p$-value $<0.001$ ), fasting plasma glucose (Spearman's rho $=-0.30, p$-value $<$ 0.001 ), postprandial plasma glucose (Spearman's rho $=-$ $0.36, p$-value $<0.001$ ), $\mathrm{HbA}_{1 \mathrm{c}}$ (Spearman's rho $=-0.38$, $p$-value $<0.001$ ), and BMI (Spearman's rho $=-0.24, p$ value $<0.001$ ). Details of the correlations are shown in Table 3. The median practice score was significantly higher for patients who were younger than 55 years $(p$ value $<0.001)$, had university education ( $p$-value $=$ $0.001)$, were diagnosed since less than 7 years ( $p$-value < $0.001)$, had attended an educational program on diabetes ( $p$-value $<0.001)$, had usual fasting glucose levels of less than $140 \mathrm{~g} / \mathrm{dL}$ ( $p$-value $<0.001)$, had usual postprandial plasma glucose of less than $200 \mathrm{~g} / \mathrm{dL}$ ( $p$-value $<0.001$ ), had $\mathrm{HbA}_{1 \mathrm{c}}<7 \%(p$-value $=0.001)$, and had a $\mathrm{BMI}<25$ $\mathrm{kg} / \mathrm{m}^{2}(p$-value $=0.001)$. Details of the differences are shown in Table 4.

\section{Predictors of higher knowledge, attitude, and practice scores}

In this study, a multiple linear regression model was used to control confounding variables and to identify predictors of higher knowledge, attitude, and practice scores. The $\mathrm{R}^{2}$ of the model was 0.22 with a $p$-value of $<0.001$. The model showed that having university education was strongly associated with having higher knowledge scores $(p$-value $=0.001)$. Additionally, the model showed that having attended an educational program on diabetes was moderately associated with higher practice scores $(p$-value $=0.026)$. Details of the multiple linear regression model are shown in Table 5.

\section{Discussion}

In this cross-sectional study, knowledge, attitude, and practice of patients with T2DM with regard to their disease were assessed for the first time among Palestinian patients. Patients who took part in this study were recruited from different primary healthcare facilities in the West Bank of Palestine. In this study, more than half (52.2\%) had good knowledge and $58.7 \%$ has positive 
Table 2 Responses of the patients on the knowledge, attitude, and practice items overall and stratified by gender ( $n=220$ )

\begin{tabular}{|c|c|c|c|c|c|c|c|c|}
\hline \multirow[t]{2}{*}{$\#$} & \multirow[t]{2}{*}{ Item } & \multicolumn{2}{|c|}{ Total } & \multicolumn{2}{|c|}{ Male } & \multicolumn{2}{|c|}{ Female } & \multirow{2}{*}{$\begin{array}{l}p \text { - } \\
\text { value }\end{array}$} \\
\hline & & $\mathbf{N}$ & $\%$ & $\mathrm{n}$ & $\%$ & $\mathrm{n}$ & $\%$ & \\
\hline \multicolumn{9}{|c|}{ Knowledge } \\
\hline \multirow[t]{3}{*}{1} & Tests used to diagnose T2DM & & & & & & & \\
\hline & Blood tests & 220 & 100.0 & 102 & 100.0 & 118 & 100.0 & 1.000 \\
\hline & Urine tests & 48 & 21.8 & 15 & 14.7 & 33 & 28.0 & 0.022 \\
\hline \multirow[t]{7}{*}{2} & Keeping blood glycemia under control & & & & & & & \\
\hline & Taking medications (insulin and/or other oral hypoglycemic agents) & 200 & 90.9 & 94 & 92.2 & 106 & 89.8 & 0.641 \\
\hline & Adhering to diet control & 174 & 79.1 & 83 & 81.4 & 91 & 77.1 & 0.507 \\
\hline & Performing regular exercise & 101 & 45.9 & 50 & 49.0 & 51 & 43.2 & 0.418 \\
\hline & Weight management & 48 & 21.8 & 21 & 20.6 & 27 & 22.9 & 0.745 \\
\hline & Going for regular checkups & 25 & 11.4 & 12 & 11.8 & 13 & 11.0 & 1.000 \\
\hline & I don't know & 7 & 3.2 & 3 & 2.9 & 4 & 3.4 & 1.000 \\
\hline \multirow[t]{3}{*}{3} & For how long should the patient adhere to diet control and/or taking medications & & & & & & & \\
\hline & Until blood sugar levels become under control & 85 & 38.6 & 36 & 35.3 & 49 & 41.5 & 0.405 \\
\hline & Lifelong & 135 & 61.4 & 66 & 64.7 & 69 & 58.5 & 0.405 \\
\hline \multirow[t]{8}{*}{4} & Major organs of the body are affected by T2DM & & & & & & & \\
\hline & Kidneys & 124 & 56.4 & 61 & 59.8 & 63 & 53.4 & 0.344 \\
\hline & Feet & 98 & 44.5 & 43 & 42.2 & 55 & 46.6 & 0.587 \\
\hline & Eyes & 129 & 58.6 & 65 & 63.7 & 64 & 54.2 & 0.171 \\
\hline & Nerves & 102 & 46.4 & 49 & 48.0 & 53 & 44.9 & 0.685 \\
\hline & Heart & 82 & 37.3 & 40 & 39.2 & 42 & 35.6 & 0.675 \\
\hline & I don't know & 21 & 9.5 & 9 & 8.8 & 12 & 10.2 & 0.820 \\
\hline & Knowledge score, Median (Q1, Q3) & & & $6.5(4$ & $4.5,7.5)$ & $5.5(4$ & $4.5,7.5)$ & 0.186 \\
\hline
\end{tabular}

\section{Attitude}

1 It is alright to eat sweets on occasional basis

Agree/undecided

$\begin{array}{llllll}80 & 36.4 & 34 & 33.3 & 46 & 39.0\end{array}$

0.402

Disagree

$\begin{array}{llllll}140 & 63.6 & 68 & 66.7 & 72 & 61.0\end{array}$

2 It is alright if you forget to take your insulin and/or other antidiabetic agents on some days
Agree/undecided
$\begin{array}{llllll}64 & 29.1 & 28 & 27.5 & 36 & 30.5\end{array}$
0.657
Disagree
$\begin{array}{llllll}156 & 70.9 & 74 & 72.5 & 82 & 69.5\end{array}$

3 Patients with T2DM should visit their healthcare providers for regular checkups even if their blood glycemia is under control
Disagree/undecided

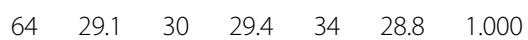
Agree
$\begin{array}{llllll}156 & 70.9 & 72 & 70.6 & 84 & 71.2\end{array}$

4 It is alright not to perform regular exercise as prescribed by the healthcare provider because patients exercise while performing daily activities
Agree/undecided
$\begin{array}{llllll}97 & 44.1 & 39 & 38.2 & 58 & 49.2\end{array}$
0.134
Disagree
$\begin{array}{llllll}123 & 55.9 & 63 & 61.8 & 60 & 50.8\end{array}$
Attitude score, Median (Q1, Q3)

\section{Practice}

1 Are you taking your insulin and/or antidiabetic agents as advised by your caring physician

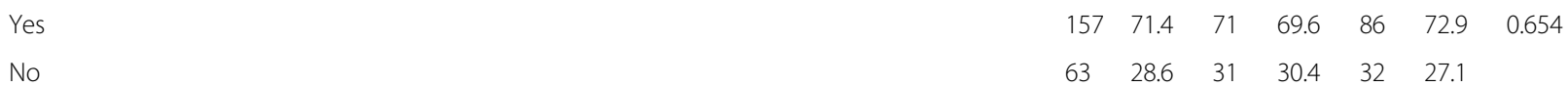

2 Are you following the diet schedule recommended to you by your healthcare providers 
Table 2 Responses of the patients on the knowledge, attitude, and practice items overall and stratified by gender ( $n=220$ ) (Continued)

\begin{tabular}{|c|c|c|c|c|c|c|c|c|}
\hline \multirow[t]{2}{*}{$\#$} & \multirow[t]{2}{*}{ Item } & \multicolumn{2}{|c|}{ Total } & \multicolumn{2}{|c|}{ Male } & \multicolumn{2}{|c|}{ Female } & \multirow{2}{*}{$\begin{array}{l}p- \\
\text { value }\end{array}$} \\
\hline & & $\mathrm{N}$ & $\%$ & $\mathbf{n}$ & $\%$ & $\mathbf{n}$ & $\%$ & \\
\hline & No & 113 & 51.4 & 52 & 51.0 & 61 & 51.7 & \\
\hline \multirow[t]{3}{*}{3} & Are you performing the regular & ders & & & & & & \\
\hline & Yes & 82 & 37.3 & 41 & 40.2 & 41 & 34.7 & 0.485 \\
\hline & No & 138 & 62.7 & 61 & 59.8 & 77 & 65.3 & \\
\hline \multirow[t]{4}{*}{4} & Is your blood glycemia under co & & & & & & & \\
\hline & Yes & 105 & 47.7 & 46 & 45.1 & 59 & 50.0 & 0.637 \\
\hline & No & 75 & 34.1 & 35 & 34.3 & 40 & 33.9 & \\
\hline & I am not sure & 40 & 18.2 & 21 & 20.6 & 19 & 16.1 & \\
\hline \multirow[t]{4}{*}{5} & Do you visit your healthcare pro & & & & & & & \\
\hline & Yes & 144 & 65.5 & 63 & 61.8 & 81 & 68.6 & 0.321 \\
\hline & No & 76 & 34.5 & 39 & 38.2 & 37 & 31.4 & \\
\hline & Practice score, Median (Q1, Q3) & & & \multicolumn{2}{|c|}{$3.0(1.0,4.0)$} & \multicolumn{2}{|c|}{$3.0(1.5,4.0)$} & 0.816 \\
\hline
\end{tabular}

Q1: 1st quartile, Q3: 3rd quartile, Median $=$ Q2

attitude with regard to their disease. On the other hand, only $36.4 \%$ had good practice. Findings of this study highlighted gaps in knowledge, attitude, and practice with regard to T2DM among patients. In this study, associations and correlations were established between knowledge, attitude, and practice with the sociodemographic and clinical characteristics of the patients. Additionally, predictors of higher knowledge, positive attitude, and good practice were identified. Findings of this study could be useful for policy makers, decision makers, healthcare providers, and patient advocacy groups who might need to design interventions to improve health outcomes of patients with T2DM.

Interestingly, there was a moderate positive correlation between knowledge, attitude, and practice scores. This could at least in part support the argument that good knowledge might promote positive attitude and adequate practice among patients with T2DM [19-21]. Our findings indicated that almost half of the patients (52.2\%) had good knowledge of T2DM and its associated complications. Patients who were young than 55 years, single, had a university education, employed, had higher income, diagnosed since less than 7 years, had usual fasting plasma glucose of less than $140 \mathrm{mg} / \mathrm{mL}$, had $\mathrm{HbA}_{1 \mathrm{c}}$ of less than $7 \%$, and had a BMI of less than $25 \mathrm{~kg} / \mathrm{m}^{2}$ scored higher in the knowledge test. In a pilot study conducted in Sri Lanka, Hearth et al. showed that 77\% of patients with T2DM has moderate or above moderate knowledge of their disease [3]. Studies in different settings have reported variable level of knowledge among patients with T2DM in Mongolia, Sri Lanka, Bangladesh, India, Jordan, and Lebanon [35-41]. When we controlled potential confounding variables, having university education was strongly associated with having higher

Table 3 Correlation between knowledge, attitude, and practice scores with socioeconomic and clinical variables of the patients

\begin{tabular}{|c|c|c|c|c|c|c|c|c|c|c|c|}
\hline Variable & & $\begin{array}{l}\text { Knowledge } \\
\text { score }\end{array}$ & $\begin{array}{l}\text { Attitude } \\
\text { score }\end{array}$ & $\begin{array}{l}\text { Practice } \\
\text { score }\end{array}$ & Age & $\begin{array}{l}\text { Monthly } \\
\text { household } \\
\text { income }\end{array}$ & $\begin{array}{l}\text { Time elapsed } \\
\text { since } \\
\text { diagnosis }\end{array}$ & $\begin{array}{l}\text { Fasting } \\
\text { plasma } \\
\text { glucose }\end{array}$ & $\begin{array}{l}\text { Postprandial } \\
\text { plasma } \\
\text { glucose }\end{array}$ & $\mathrm{HbA}_{1 \mathrm{c}}$ & $\begin{array}{l}\text { Body } \\
\text { Mass } \\
\text { Index }\end{array}$ \\
\hline \multirow{2}{*}{$\begin{array}{l}\text { Knowledge } \\
\text { score }\end{array}$} & rho & - & 0.34 & 0.46 & -0.26 & 0.27 & -0.19 & -0.24 & -0.18 & -0.17 & -0.13 \\
\hline & $\begin{array}{l}p- \\
\text { value }\end{array}$ & & $<0.001$ & $<0.001$ & $\begin{array}{l}< \\
0.001\end{array}$ & $<0.001$ & 0.004 & $<0.001$ & 0.007 & 0.015 & 0.056 \\
\hline \multirow{2}{*}{$\begin{array}{l}\text { Attitude } \\
\text { score }\end{array}$} & rho & 0.34 & - & 0.49 & 0.00 & 0.08 & 0.00 & -0.24 & -0.24 & -0.14 & -0.19 \\
\hline & $\begin{array}{l}p- \\
\text { value }\end{array}$ & $<0.001$ & & $<0.001$ & 0.958 & 0.221 & 0.997 & $<0.001$ & $<0.001$ & 0.048 & 0.005 \\
\hline \multirow[t]{2}{*}{$\begin{array}{l}\text { Practice } \\
\text { score }\end{array}$} & rho & 0.46 & 0.49 & - & $\overline{-}-24$ & 0.11 & -0.30 & -0.30 & -0.36 & -0.38 & -0.24 \\
\hline & $\begin{array}{l}p- \\
\text { value }\end{array}$ & $<0.001$ & $<0.001$ & & $\begin{array}{l}< \\
0.001\end{array}$ & 0.116 & $<0.001$ & $<0.001$ & $<0.001$ & $\begin{array}{l}< \\
0.001\end{array}$ & $<0.001$ \\
\hline
\end{tabular}


Table 4 Differences in knowledge, attitude, and practice scores among the patients stratified by their sociodemographic and clinical variables

\begin{tabular}{|c|c|c|c|c|c|c|c|c|}
\hline \multirow[t]{2}{*}{ Variable } & \multirow[t]{2}{*}{$\mathbf{n}$} & \multirow[t]{2}{*}{$\%$} & \multicolumn{2}{|l|}{ Knowledge } & \multicolumn{2}{|l|}{ Attitude } & \multicolumn{2}{|l|}{ Practice } \\
\hline & & & $\overline{\text { Median }(\mathrm{Q} 1, \mathrm{Q})}$ & $p$-value & Median (Q1, Q3) & $p$-value & $\overline{\text { Median (Q1, Q3) }}$ & $p$-value \\
\hline \multicolumn{9}{|l|}{ Age (years) } \\
\hline$<55$ & 82 & 37.3 & $6.5(5.5,8.5)$ & $<0.001$ & $3.0(2.0,4.0)$ & 0.979 & $4.0(2.0,4.0)$ & $<0.001$ \\
\hline$\geq 55$ & 138 & 62.7 & $5.5(3.5,7.5)$ & & $3.0(2.0,4.0)$ & & $3.0(1.0,4.0)$ & \\
\hline \multicolumn{9}{|l|}{ Gender } \\
\hline Male & 102 & 46.4 & $6.5(4.5,7.5)$ & 0.186 & $3.0(2.0,4.0)$ & 0.288 & $3.0(1.0,4.0)$ & 0.816 \\
\hline Female & 118 & 53.6 & $5.5(4.0,7.5)$ & & $3.0(2.0,4.0)$ & & $3.0(1.8,4.0)$ & \\
\hline \multicolumn{9}{|l|}{ Marital status } \\
\hline Single & 32 & 14.5 & $7.3(6.1,8.5)$ & 0.021 & $2.5(2.0,4.0)$ & 0.722 & $3.0(1.0,5.0)$ & 0.561 \\
\hline Married & 156 & 70.9 & $5.5(4.5,7.5)$ & & $3.0(2.0,4.0)$ & & $3.0(2.0,4.0)$ & \\
\hline Divorced/widowed & 32 & 14.5 & $6.5(3.5,8.8)$ & & $3.0(2.0,4.0)$ & & $3.0(1.0,3.8)$ & \\
\hline \multicolumn{9}{|l|}{ Employment } \\
\hline Unemployed & 139 & 63.2 & $5.5(4.0,7.50$ & 0.001 & $3.0(2.0,4.0)$ & 0.659 & $3.0(1.0,4.0)$ & 0.230 \\
\hline Employed & 81 & 36.8 & $6.595 .5,8.3)$ & & $3.0(2.0,4.0)$ & & $3.0(1.0,4.0)$ & \\
\hline \multicolumn{9}{|l|}{ Place of residence } \\
\hline Urban & 149 & 67.7 & $6.5(4.5,7.5)$ & 0.520 & $3.0(2.0,4.0)$ & 0.853 & $3.0(1.0,4.0)$ & 0.863 \\
\hline Country side & 71 & 32.3 & $5.5(4.5,7.5)$ & & $3.0(2.0,4.0)$ & & $3.0(2.0,4.0)$ & \\
\hline \multicolumn{9}{|l|}{ Educational level } \\
\hline Some school & 165 & 75 & $5.5(4.0,7.0)$ & $<0.001$ & $3.0(2.0,4.0)$ & 0.253 & $3.0(1.0,4.0)$ & 0.001 \\
\hline University & 55 & 25 & $7.5(5.5,10.0)$ & & $3.0(2.0,4.0)$ & & $4.0(2.0,5.0)$ & \\
\hline \multicolumn{9}{|c|}{ Monthly household income (Jordanian Dinar) } \\
\hline$<600$ & 85 & 38.6 & $5.5(4.0,6.5)$ & $<0.001$ & $2.0(2.0,4.0)$ & 0.290 & $3.0(1.0,4.0)$ & 0.192 \\
\hline $600-1000$ & 93 & 42.3 & $6.5(5.0,7.5)$ & & $3.0(2.0,4.0)$ & & $3.0(1.0,4.0)$ & \\
\hline$\geq 1000$ & 42 & 19.1 & $7.5(4.5,9.5)$ & & $3.0(1.8,4.0)$ & & $3.0(2.0,4.0)$ & \\
\hline \multicolumn{9}{|c|}{ Time elapsed since diagnosis (years) } \\
\hline$<7$ & 104 & 47.3 & $6.5(5.0,8.5)$ & 0.001 & $3.0(2.0,4.0)$ & 0.892 & $4.0(2.0,5.0)$ & $<0.001$ \\
\hline$\geq 7$ & 116 & 52.7 & $5.5(4.0,7.5)$ & & $3.0(2.0,4.0)$ & & $3.0(0.3,3.0)$ & \\
\hline \multicolumn{9}{|l|}{ Has a health insurance } \\
\hline Yes & 175 & 79.5 & $6.0(4.5,7.5)$ & 0.230 & $3.0(2.0,4.0)$ & 0.255 & $3.0(1.0,4.0)$ & 0.257 \\
\hline No & 45 & 20.5 & $6.5(4.5,8.3)$ & & $3.0(2.0,4.0)$ & & $3.0(1.0,5.0)$ & \\
\hline \multicolumn{9}{|c|}{ Has attended educational program regarding diabetes } \\
\hline Yes & 22 & 10 & $6.0(4.5,7.5)$ & 0.969 & $3.0(2.0,4.0)$ & 0.547 & $3.5(3.0,4.0)$ & 0.026 \\
\hline No & 198 & 90 & $6.5(4.5,7.5)$ & & $3.0(2.0,4.0)$ & & $3.0(1.0,4.0)$ & \\
\hline \multicolumn{9}{|c|}{ Fasting plasma glucose $(\mathrm{mg} / \mathrm{dL})$} \\
\hline$<140$ & 66 & 30 & $6.5(5.0,8.5)$ & 0.003 & $3.0(2.0,4.0)$ & 0.013 & $4.0(2.0,5.0)$ & $<0.001$ \\
\hline$\geq 140$ & 154 & 70 & $5.5(4.5,7.5)$ & & $3.0(2.0,4.0)$ & & $3.0(1.0,4.0)$ & \\
\hline \multicolumn{9}{|c|}{ Postprandial plasma glucose (mg/dL) } \\
\hline$<200$ & 43 & 19.5 & $6.5(4.0,8.5)$ & 0.423 & $3.0(2.0,4.0)$ & 0.114 & $4.0(3.0,5.0)$ & $<0.001$ \\
\hline$\geq 200$ & 177 & 80.5 & $6.0(4.5,7.5)$ & & $3.0(2.0,4.0)$ & & $3.0(1.0,4.0)$ & \\
\hline \multicolumn{9}{|l|}{$\mathrm{HbA}_{1 \mathrm{c}}(\%)$} \\
\hline$<7$ & 53 & 24.1 & $6.5(4.8,9.5)$ & 0.037 & $3.0(2.0,4.0)$ & 0.301 & $4.0(3.0,4.0)$ & 0.001 \\
\hline$\geq 7$ & 167 & 75.9 & $5.5(4.5,7.5)$ & & $3.0(2.0,4.0)$ & & $3.0(1.0,4.0)$ & \\
\hline
\end{tabular}

Body Mass Index $\left(\mathrm{kg} / \mathrm{m}^{2}\right)$ 
Table 4 Differences in knowledge, attitude, and practice scores among the patients stratified by their sociodemographic and clinical variables (Continued)

\begin{tabular}{|c|c|c|c|c|c|c|c|c|}
\hline \multirow[t]{2}{*}{ Variable } & \multirow[t]{2}{*}{$n$} & \multirow[t]{2}{*}{$\%$} & \multicolumn{2}{|l|}{ Knowledge } & \multicolumn{2}{|l|}{ Attitude } & \multicolumn{2}{|l|}{ Practice } \\
\hline & & & Median (Q1, Q3) & $p$-value & Median (Q1, Q3) & $p$-value & Median (Q1, Q3) & $p$-value \\
\hline$<25$ & 45 & 20.5 & $6.5(5.0,8.5)$ & 0.039 & $3.0(2.0,4.0)$ & 0.211 & $4.092 .5,5.0)$ & 0.001 \\
\hline$\geq 25$ & 175 & 79.5 & $5.5(4.5,7.5)$ & & $3.0(2.0,4.0)$ & & $3.0(1.0,4.0)$ & \\
\hline
\end{tabular}

$\mathrm{HbA}_{1 c}$ Glycated hemoglobin, Q1: 1st quartile, Q3: 3rd quartile, Median = Q2

knowledge scores. Findings of this study might indicate that educated patients are more likely to be more aware of their disease, its complications, and ways to keep their blood glucose under control. Additionally, it has been argued that university educated patients are more likely to be interested in learning about their disease compared to uneducated patients who might be less interest in learning about their diseases. Taken together, our findings might suggest that less educated patients need greater motivation and support from their healthcare providers and families. Our findings were consistent with those reported in previous studies that were conducted elsewhere [3, 36, 37]. For example, Hearth et al. showed that education was positively associated with higher knowledge of T2DM among patients in Sri Lanka [3]. Similarly, Karaoui et al. showed that higher level of education was positively correlated with higher knowledge of T2DM among patients in Lebanon [37]. In Bangladesh, Fatema et al. showed that male patients with T2DM had significantly higher knowledge of their disease compared to female patients [36].

Findings of this study showed that $58.7 \%$ of the patients had positive attitudes toward their disease. Attitude scores were positively associated with ability to keep a usual fasting plasma glucose level below $140 \mathrm{mg} /$ $\mathrm{dL}$, postprandial plasma glucose level below $200 \mathrm{mg} / \mathrm{dL}$, $\mathrm{HbA}_{1 \mathrm{c}}$ below $7 \%$, and BMI below $25 \mathrm{~kg} / \mathrm{m}^{2}$. When we controlled potential confounding variables, attitude scores were no longer associated with these variables. Findings of this study were contradictory to those reported by Belsti et al. in Ethiopia in which attitudes of the patients were associated with their educational level and income [26]. Previous studies suggested that patients with higher income could have better access to healthcare services, ability to go to regular checkups, and practice physical activity compared to patients with less income $[25,36]$.

Regarding practice, our study showed that $36.4 \%$ of the patients with T2DM had good practices with regard to their disease. Patients who were younger than 55 years, had university education, were diagnosed since less than 7 years, had attended an educational program on diabetes, had a usual fasting glucose levels of less than $140 \mathrm{~g} / \mathrm{dL}$, had postprandial plasma glucose of less than $200 \mathrm{~g} / \mathrm{dL}(p$-value $<0.001)$, had $\mathrm{HbA}_{1 \mathrm{c}}$ of less than
$7 \%$, and had a BMI of less than $25 \mathrm{~kg} / \mathrm{m}^{2}$ reported higher practice scores. Our results were consistent with those reported in different settings in Ethiopia, Mongolia, Sri Lanka, Bangladesh, and Lebanon [3, 26, 35-37]. When we controlled potential confounding variables, having attended an educational program on diabetes was moderately associated with higher practice scores. Our findings might support previous findings on the effectiveness of educational programs in improving selfmanagement and health outcomes in patients with T2DM $[42,43]$.

\section{Strengths and limitations}

Results of this study might be carefully interpreted taking into consideration the following strengths and limitations. First, this study was the first to assess knowledge, attitude, and practice of Palestinians with T2DM with regard to their disease. The tool used to measure knowledge, attitude, and practice was adopted from previous studies [24-26]. The tool was piloted for clarity and comprehension. Additional face validity, testing for stability of scores over a short period of time, and internal consistency between the items included were performed. The test-retest method and Cronbach's alpha ensured that the tool used in this study was reliable and internally consistent [28-32]. These measures might have added strength and rigor to methods used in this study. Second, the data were collected using an interviewer administered questionnaire. Additionally, the interviewers in this study were final year MD candidates who were familiar with conducting interviews and taking patient history. This could have minimized occasions of mis- or lack of understanding associated with selfadministered questionnaires [44]. Third, this study also established associations and correlations between knowledge, attitude, and practice with various sociodemographic and clinical characteristics of the patients. Fourth, predictors of higher knowledge, attitude, and practice scores were also identified in this study. Fifth, the study tool used in this study was piloted and evaluated for reliability and internal consistency. Finally, the study tool was administered by interviewers who were final year MD candidates who were familiar with interviewing patients and taking medical history. This could have reduced the occasions of mis- or lack of 
Table 5 Multiple linear regression between sociodemographic and clinical variables of the patients with knowledge, attitude, and practice scores

\begin{tabular}{|c|c|c|c|c|c|}
\hline Variable & Unadjusted Coefficients & SE & Adjusted Coefficients & $\mathbf{t}$ & $p$-value \\
\hline \multicolumn{6}{|l|}{ Knowledge score } \\
\hline Gender & -0.03 & 0.38 & -0.01 & -0.07 & 0.942 \\
\hline Marital status & -0.01 & 0.32 & 0.00 & -0.03 & 0.979 \\
\hline Employment & 0.13 & 0.44 & 0.03 & 0.30 & 0.762 \\
\hline Place of residence & -0.18 & 0.35 & -0.03 & -0.51 & 0.609 \\
\hline Educational level & 1.47 & 0.42 & 0.27 & 3.49 & 0.001 \\
\hline Monthly income & 0.43 & 0.25 & 0.13 & 1.71 & 0.088 \\
\hline Having a health insurance & -0.40 & 0.40 & -0.07 & -1.02 & 0.307 \\
\hline Having attended an educational program & 0.23 & 0.55 & 0.03 & 0.42 & 0.676 \\
\hline Age & -0.04 & 0.02 & -0.17 & -1.82 & 0.070 \\
\hline Time elapsed since diagnosis & 0.03 & 0.03 & 0.09 & 0.97 & 0.332 \\
\hline Body Mass Index & 0.00 & 0.03 & 0.00 & 0.01 & 0.990 \\
\hline Fasting plasma glucose & -0.01 & 0.01 & -0.19 & -1.55 & 0.123 \\
\hline Postprandial plasma glucose & 0.00 & 0.01 & -0.02 & -0.14 & 0.887 \\
\hline $\mathrm{HbA}_{1 \mathrm{c}}$ & 0.10 & 0.18 & 0.06 & 0.57 & 0.568 \\
\hline \multicolumn{6}{|l|}{ Attitude score } \\
\hline Gender & -0.20 & 0.21 & -0.08 & -0.96 & 0.338 \\
\hline Marital status & 0.11 & 0.18 & 0.05 & 0.60 & 0.552 \\
\hline Employment & 0.01 & 0.25 & 0.00 & 0.04 & 0.966 \\
\hline Place of residence & -0.08 & 0.20 & -0.03 & -0.40 & 0.687 \\
\hline Educational level & 0.12 & 0.24 & 0.04 & 0.50 & 0.617 \\
\hline Monthly income & 0.00 & 0.14 & 0.00 & -0.02 & 0.982 \\
\hline Having a health insurance & -0.13 & 0.22 & -0.04 & -0.59 & 0.554 \\
\hline Having attended an educational program & 0.12 & 0.31 & 0.03 & 0.40 & 0.689 \\
\hline Age & 0.00 & 0.01 & 0.00 & -0.03 & 0.977 \\
\hline Time elapsed since diagnosis & 0.01 & 0.02 & 0.08 & 0.80 & 0.426 \\
\hline Body Mass Index & -0.02 & 0.02 & -0.09 & -1.25 & 0.211 \\
\hline Fasting plasma glucose & 0.00 & 0.00 & -0.01 & -0.04 & 0.964 \\
\hline Postprandial plasma glucose & -0.01 & 0.00 & -0.30 & -1.86 & 0.064 \\
\hline $\mathrm{HbA}_{1 \mathrm{c}}$ & 0.08 & 0.10 & 0.09 & 0.79 & 0.432 \\
\hline \multicolumn{6}{|l|}{ Practice score } \\
\hline Gender & -0.16 & 0.26 & -0.05 & -0.62 & 0.536 \\
\hline Marital status & -0.05 & 0.22 & -0.02 & -0.24 & 0.813 \\
\hline Employment & -0.26 & 0.30 & -0.08 & -0.86 & 0.393 \\
\hline Place of residence & 0.03 & 0.24 & 0.01 & 0.14 & 0.891 \\
\hline Educational level & 0.35 & 0.29 & 0.09 & 1.20 & 0.232 \\
\hline Monthly income & -0.03 & 0.17 & -0.01 & -0.15 & 0.882 \\
\hline Having a health insurance & -0.14 & 0.27 & -0.03 & -0.53 & 0.599 \\
\hline Having attended an educational program & 0.85 & 0.38 & 0.15 & 2.24 & 0.026 \\
\hline Age & -0.01 & 0.01 & -0.09 & -0.93 & 0.353 \\
\hline Time elapsed since diagnosis & -0.02 & 0.02 & -0.09 & -0.97 & 0.333 \\
\hline Body Mass Index & -0.03 & 0.02 & -0.11 & -1.57 & 0.119 \\
\hline Fasting plasma glucose & 0.01 & 0.01 & 0.13 & 1.07 & 0.287 \\
\hline
\end{tabular}


Table 5 Multiple linear regression between sociodemographic and clinical variables of the patients with knowledge, attitude, and practice scores (Continued)

\begin{tabular}{|c|c|c|c|c|c|}
\hline Variable & Unadjusted Coefficients & SE & Adjusted Coefficients & $\mathbf{t}$ & $p$-value \\
\hline Postprandial plasma glucose & -0.01 & 0.00 & -0.28 & -1.84 & 0.068 \\
\hline $\mathrm{HbA}_{1 \mathrm{c}}$ & -0.15 & 0.12 & -0.13 & -1.19 & 0.234 \\
\hline
\end{tabular}

$H b A_{1 c}$ Glycated hemoglobin, SE standard error, $t$ t statistic

understanding that could be associated with selfadministered questionnaires.

On the other hand, this study has a number of limitations. First, this study was a cross-sectional study. An interventional design could have permitted enhancing knowledge, improved positive attitude, and promoted good practice among patients with T2DM with regard to their disease. Second, the sample size used in this study was relatively small. However, the sample size used in this study was comparable to those used in other studies $[3,37]$. Third, a convenience sampling method was followed to recruit the sample needed for this study. It is noteworthy mentioning that the sample recruited in this study was diversified by inclusion of patients from both genders, different educational levels, income levels, and geographic locations. Finally, the number of items relevant to knowledge, attitude, and practice was relatively small. Despite the small number of items, we were able to expose the level of knowledge, attitude, and practice of patients with T2DM with regard to their disease.

\section{Conclusion}

In conclusion, this study provided insights into knowledge, attitude, and practice of Palestinians with T2DM. The study established association and correlation between knowledge, attitude, and practice scores with sociodemographic and clinical characteristics of patients with T2DM in Palestine. Findings of this study highlighted the need for appropriately designed interventions to increase knowledge about T2DM among patients with low educational level. Well-designed educational programs might promote healthy practice among patients with T2DM. Future studies are still needed to assess if such interventions could be effective in improving health outcomes and quality of life of patients with T2DM in Palestine.

\section{Abbreviations}

BMl: Body mass index; T2DM: Type 2 diabetes mellitus; HbA 1 : Glycated hemoglobin; IRB: Institutional Board Review; MD: Doctor of Medicine; Q1: 1st quartile; Q2: 2nd quartile (median); Q3: 3rd quartile

\section{Acknowledgements}

Authors would like to thank the patients who participated in the study. AnNajah National University is acknowledged for making this study possible.

\section{Authors' contributions}

RS was involved in the conception and design of the work, analysis and interpretation of data, drafting and final approval the manuscript. SS and AZ were involved in the data acquisition, analysis, drafting the work and final approval of the version to be published.

\section{Authors' information}

Ramzi Shawahna, Associate Professor, Department of Physiology,

Pharmacology and Toxicology, Faculty of Medicine and Health Sciences, AnNajah National University, Nablus, Palestine, An-Najah BioSciences Unit, Centre for Poisons Control, Chemical and Biological Analyses, An-Najah National University, Nablus, Palestine. Saed Samaro and Zaid Ahmad are Doctor of Medicine candidates, Department of Medicine, Faculty of Medicine and Health Sciences, An-Najah National University, Nablus, Palestine.

\section{Funding}

This study did not receive any specific funding.

\section{Availability of data and materials}

The datasets used and/or analyzed during the current study are available from the corresponding author on reasonable request.

\section{Declarations}

Ethics approval and consent to participate

Ethics approval was obtained from the Institutional Board Review (IRB) of AnNajah National University. Field researchers explained the study design and objectives to the potential participants and obtained their written informed consent before they took part in the present study. The IRB of An-Najah National University approved a verbal consent for this study. Approval was obtained from the Ministry of Health to access the healthcare centers.

\section{Consent for publication}

Not applicable.

\section{Competing interests}

All authors report no competing interests.

\section{Author details}

'Department of Physiology, Pharmacology and Toxicology, Faculty of Medicine \& Health Sciences, New Campus, Building: 19, Office: 1340, An-Najah National University, P.O. Box 7, Nablus, Palestine. ${ }^{2}$ An-Najah BioSciences Unit, Centre for Poisons Control, Chemical and Biological Analyses, An-Najah National University, Nablus, Palestine. ${ }^{3}$ Department of Medicine, Faculty of Medicine and Health Sciences, An-Najah National University, Nablus, Palestine.

Received: 2 November 2020 Accepted: 1 March 2021

Published online: 09 March 2021

References

1. Hartayu TS, Mi MI, Suryawati S. Improving of type 2 diabetic patients' knowledge, attitude and practice towards diabetes self-care by implementing community-based interactive approach-diabetes mellitus strategy. BMC Res Notes. 2012;5:315.

2. de Gennaro G, Palla G, Battini L, Simoncini T. The role of adipokines in the pathogenesis of gestational diabetes mellitus. Gynecol Endocrinol. 2019; 35(9):737-51.

3. Herath HMM, Weerasinghe NP, Dias H, Weerarathna TP. Knowledge, attitude and practice related to diabetes mellitus among the general public in Galle district in southern Sri Lanka: a pilot study. BMC Public Health. 2017;17(1): 535.

4. Khan MAB, Hashim MJ, King JK, Govender RD, Mustafa H, Al Kaabi J. Epidemiology of type 2 diabetes - global burden of disease and forecasted trends. J Epidemiol Glob Health. 2020;10(1):107-11. 
5. Abu-Rmeileh NME, Husseini A, O'Flaherty M, Shoaibi A, Capewell S. Forecasting prevalence of type 2 diabetes mellitus in Palestinians to 2030: validation of a predictive model. Lancet. 2012;380:S21.

6. Verhulst MJL, Loos BG, Gerdes VEA, Teeuw WJ. Evaluating all potential Oral complications of diabetes mellitus. Front Endocrinol. 2019;10:56.

7. Nathan DM, Bennett PH, Crandall JP, Edelstein SL, Goldberg RB, Kahn SE, Knowler WC, Mather KJ, Mudaliar S, Orchard TJ, et al. Does diabetes prevention translate into reduced long-term vascular complications of diabetes? Diabetologia. 2019;62(8):1319-28.

8. Marx N. New ESC guidelines 2019 "Diabetes, prediabetes and cardiovascular diseases": Paradigm shift in reduction of cardiovascular risk in patients with diabetes mellitus. Herz. 2019:44(8):684-7.

9. Das A. Fighting diabetic blindness: an urgent global issue concerning patients, physicians and public policy. Indian J Ophthalmol. 2020;68(Suppl 1):S6-7.

10. Maiorino MI, Signoriello S, Maio A, Chiodini P, Bellastella G, Scappaticcio L, Longo M, Giugliano D. Effects of continuous glucose monitoring on metrics of glycemic control in diabetes: a systematic review with meta-analysis of randomized controlled trials. Diabetes Care. 2020;43(5):1146-56.

11. Khunti K, Giorgino F, Berard L. The importance of the initial period of basal insulin titration in people with diabetes. Diabet Obes Metabol. 2020;22(5): 722-33.

12. Felix HC, Narcisse MR, Long CR, English E, Haggard-Duff L, Purvis RS, McElfish PA. The effect of family diabetes self-management education on self-care behaviors of Marshallese adults with type 2 diabetes. Am J Health Behav. 2019;43(3):490-7.

13. Sinclair AJ, Abdelhafiz AH, Forbes A. Evidence-based diabetes care for older people with Type 2 diabetes: a critical review. Diabet Med. 2019;36(4):399413.

14. Zheng Y, Ley SH, Hu FB. Global aetiology and epidemiology of type 2 diabetes mellitus and its complications. Nat Rev Endocrinol. 2018;14(2):8898.

15. Abu-Amara TB, Al Rashed WA, Khandekar R, Qabha HM, Alosaimi FM, Alshuwayrikh AA, Almadi MK, Alfaris A. Knowledge, attitude and practice among non-ophthalmic health care providers regarding eye management of diabetics in private sector of Riyadh, Saudi Arabia. BMC Health Serv Res. 2019;19(1):375.

16. Chawla SPS, Kaur S, Bharti A, Garg R, Kaur M, Soin D, Ghosh A, Pal R. Impact of health education on knowledge, attitude, practices and glycemic control in type 2 diabetes mellitus. J Fam Med Prim Care. 2019;8(1):261-8.

17. Asmelash D, Abdu N, Tefera S, Baynes HW. Knowledge, attitude, and practice towards glycemic control and its associated factors among diabetes mellitus patients. J Diabet Res. 2019;2019:2593684.

18. Aljofan M, Altebainawi A, Alrashidi MN. Public knowledge, attitude and practice toward diabetes mellitus in hail region, Saudi Arabia. Int I Gen Med. 2019;12:255-62.

19. Nassar CM, Montero A, Magee MF. Inpatient diabetes education in the real world: an overview of guidelines and delivery models. Curr Diabetes Rep. 2019;19(10):103

20. Fan L, Sidani S. Factors influencing preferences of adults with type 2 diabetes for diabetes self-management education interventions. Can J Diabetes. 2018;42(6):645-51.

21. Rani PK, Raman R, Subramani S, Perumal G, Kumaramanickavel G, Sharma T. Knowledge of diabetes and diabetic retinopathy among rural populations in India, and the influence of knowledge of diabetic retinopathy on attitude and practice. Rural Remote Health. 2008;8(3):838.

22. Blasco-Blasco M, Puig-García M, Piay N, Lumbreras B, Hernández-Aguado I, Parker LA. Barriers and facilitators to successful management of type 2 diabetes mellitus in Latin America and the Caribbean: A systematic review. PloS one. 2020;15(9):e0237542.

23. Palestine [https://idf.org/our-network/regions-members/middle-east-andnorth-africa/members/44-palestine.html]. Accessed 11 Jan 2021.

24. Srinivasan NK, John D, Rebekah G, Kujur ES, Paul P, John SS. Diabetes and diabetic retinopathy: knowledge, attitude, practice (KAP) among diabetic patients in a tertiary eye care Centre. J Clin Diagn Res. 2017;11(7):NC01-7.

25. Rahaman KS, Majdzadeh R, Holakouie Naieni K, Raza O. Knowledge, attitude and practices (KAP) regarding chronic complications of diabetes among patients with type 2 diabetes in Dhaka. Int J Endocrinol Metabol. 2017;15(3): e12555

26. Belsti $Y$, Akalu Y, Animut Y. Attitude, practice and its associated factors towards diabetes complications among type 2 diabetic patients at Addis
Zemen District hospital, Northwest Ethiopia. BMC Public Health. 2020;20(1): 785.

27. Butler R, McClinchy J, Morreale-Parker C, Marsh W, Rennie KL. BMI calculation in older people: the effect of using direct and surrogate measures of height in a community-based setting. Clin Nutr ESPEN. 2017;22: $112-5$.

28. Shawahna R, Khaskiyyi M. Palestinian pharmacists' knowledge of issues related to using psychotropic medications in older people: a cross-sectional study. J Educ Eval Health Prof. 2017;14(8).

29. Shawahna R, Fahed B, Qadri D, Sharawi L, Soroghli M, Dweik M. Awareness and knowledge of autism Spectrum disorders among pharmacists: a crosssectional study in Palestinian pharmacy practice. J Autism Dev Disord. 2017; 47(6):1618-27.

30. Shawahna R, Atrash A, Jebril A, Khalaf A, Shaheen E, Tahboosh H. Evaluation of pharmacists' knowledge of women's issues in epilepsy: a cross-sectional study in Palestinian pharmacy practice. Seizure. 2017;46:1-6.

31. Shawahna R, Atrash A, Jebril A, Khalaf A, Shaheen E, Tahboosh H. Pharmacists' knowledge of issues in pharmacotherapy of epilepsy using antiepileptic drugs: a cross-sectional study in Palestinian pharmacy practice. Epilepsy Behav. 2017:67:39-44.

32. Shawahna R, Al-Rjoub M. Risk of error estimated from Palestine pharmacists' knowledge and certainty on the adverse effects and contraindications of active pharmaceutical ingredients and excipients. J Educ Eval Health Prof. 2016;13:1.

33. Shawahna R, Haddad A, Khawaja B, Raie R, Zaneen S, Edais T. Medication dispensing errors in Palestinian community pharmacy practice: a formal consensus using the Delphi technique. Int J Clin Pharm. 2016;38(5):1112-23.

34. Shawahna R, Zyoud A, Jallad D, Hadwan L, Ihssan N, Hilal H. Blood zinc levels in nursing women from different regions of the West Bank of Palestine. Women Health. 2018;58(7):822-33.

35. Demaio AR, Otgontuya D, de Courten M, Bygbjerg IC, Enkhtuya P, Oyunbileg J, Meyrowitsch DW. Exploring knowledge, attitudes and practices related to diabetes in Mongolia: a national population-based survey. BMC Public Health. 2013;13:236.

36. Fatema K, Hossain S, Natasha K, Chowdhury HA, Akter J, Khan T, Ali L. Knowledge attitude and practice regarding diabetes mellitus among nondiabetic and diabetic study participants in Bangladesh. BMC Public Health. 2017;17(1):364.

37. Karaoui LR, Deeb ME, Nasser L, Hallit S. Knowledge and practice of patients with diabetes mellitus in Lebanon: a cross-sectional study. BMC Public Health. 2018;18(1):525.

38. Alsous M, Abdel Jalil M, Odeh M, Al Kurdi R, Alnan M. Public knowledge, attitudes and practices toward diabetes mellitus: a cross-sectional study from Jordan. PLoS One. 2019;14(3):e0214479.

39. Saleh F, Mumu SJ, Ara F, Begum HA, Ali L. Knowledge and self-care practices regarding diabetes among newly diagnosed type 2 diabetics in Bangladesh: a cross-sectional study. BMC Public Health. 2012;12:1112.

40. Deepa M, Bhansali A, Anjana RM, Pradeepa R, Joshi SR, Joshi PP, Dhandhania VK, Rao PV, Subashini R, Unnikrishnan R, et al. Knowledge and awareness of diabetes in urban and rural India: the Indian Council of Medical Research India diabetes study (phase I): Indian Council of Medical Research India diabetes 4. Indian J Endocrinol Metabol. 2014;18(3):379-85.

41. Shah VN, Kamdar PK, Shah N. Assessing the knowledge, attitudes and practice of type 2 diabetes among patients of Saurashtra region, Gujarat. Int J Diabet Dev Ctries. 2009;29(3):118-22.

42. Chatterjee S, Davies MJ, Heller S, Speight J, Snoek FJ, Khunti K. Diabetes structured self-management education programmes: a narrative review and current innovations. Lancet Diabet Endocrinol. 2018;6(2):130-42.

43. Rashed OA, Sabbah HA, Younis MZ, Kisa A, Parkash J. Diabetes education program for people with type 2 diabetes: an international perspective. Eval Program Plan. 2016;56:64-8.

44. Brassard D, Laramée C, Robitaille J, Lemieux S, Lamarche B. Differences in population-based dietary intake estimates obtained from an intervieweradministered and a self-administered web-based 24-h recall. Front Nutr. 2020;7:137.

\section{Publisher's Note}

Springer Nature remains neutral with regard to jurisdictional claims in published maps and institutional affiliations. 